ÁREA ABIERTA. Vol. 14, $n^{\circ}$ 3. Numero monográfico "Feminismo, estudios sobre mujeres y cultura audiovisual". Noviembre 2014

http://dx.doi.org/10.5209/rev_ARAB.2014.v14.n3.46775

"LA ACTIVIDAD DE LAS MUJERES ADOLESCENTES MIGRANTES

EN EL ENTORNO DIGITAL: ACCESO, USO Y VISIBILIDAD"

AUTORAS: Amparo HUERTAS BAILÉN, Universitat Autònoma de Barcelona, España; Yolanda MARTíneZ SUÁREZ y Saleta DE SALVADOR AGRA, Universidad Técnica Particular de Loja, Ecuador

\title{
La actividad de las mujeres adolescentes migrantes en el entorno digital: acceso, uso y visibilidad
}

\section{The activity of adolescent migrant women in the digital environment: access, use and visibility}




\title{
RESUMEN:
}

Internet ocupa un lugar central en la vida cotidiana, por lo que es necesario analizar el modo en que la ciudadanía hace uso de ese entorno digital. Nuestro objetivo es aproximarnos a ese conocimiento desde la perspectiva de género. Nos centramos en el colectivo de mujeres migrantes, en las que se suma la discriminación de género y de origen cultural, y focalizamos el estudio en la adolescencia, la etapa vital donde la urgencia de consolidar una identidad propia se hace más evidente. Este artículo presenta algunos de los resultados del proyecto "Las relaciones sociales de los jóvenes migrantes en Internet desde la perspectiva de la interculturalidad" (CSO2011-24376). Se ha trabajado con una muestra formada por 72 jóvenes (de 12 a 17 años) residentes en tres provincias españolas (Vizcaya, Madrid y Barcelona). Se aplicó un cuestionario semiestructurado, focus groups y talleres ad hoc. En relación a la conducta en el entorno digital, aunque aparecen los estereotipos de género, las fronteras parecen comenzar a diluirse. En cambio, si observamos la percepción del comportamiento, se detecta un fuerte arraigo de la heterodesignación.

\section{Palabras clave:}

Adolescencia, género, migración, Internet, Redes Sociales Digitales.

\begin{abstract}
:
Internet occupies an important place in everyday life, so it is necessary to analyze how the public uses it such digital environment. Our goal is to approach that knowledge from the perspective of gender. We focus on migrant women, taking in account that gender discrimination adds to racial discrimination, and on adolescent life stage, which is marked by the need to consolidate an identity. This article presents some of the results obtained from the project "Migrant Youths' Online Social Relationships from the Perspective of Interculturality" (CSO2011-24376). The study sample comprised 72 young migrants (aged 12-17 years) living in three provinces of Spain (Vizcaya, Madrid and Barcelona). Semistructured questionnaires, focus groups and ad hoc workshop were conducted. Regarding the behavior in the digital environment, although gender stereotypes appear, borders seem to start to fade. However, if we observe perceived behavior, highlight heterodesignation's processes.
\end{abstract}

\section{Key words:}

Adolescence, gender, migration, Internet, Digital Social Networks. 


\section{Introducción}

El libro Gender und Medien (Género y Medios), publicado en 1994 y coordinado por Marie-Luise Angerer y Johanna Dorer, es una de las recopilaciones disponibles de las líneas de reflexión desarrolladas durante el siglo XX en el área de la comunicación audiovisual derivadas de la perspectiva feminista. Según recoge este texto, la mayor parte de los trabajos se centran en las mujeres o "lo femenino" y pueden ser clasificados, en su conjunto, en dos áreas temáticas: socialización y recepción. En lo que se refiere a la socialización, entendiendo como tal los imaginarios y valores que los medios difunden, esta publicación apunta que dos ejes temáticos habituales son las "relaciones sexuales patriarcales" y el estereotipo de la "mujer ideal" como madre y esposa. Sobre la recepción, el texto revela como principal foco de atención del siglo pasado el seguimiento de radio-novelas y soap operas (seriales de televisión) por parte de las mujeres y, más concretamente, los efectos negativos de las historias basadas en el "amor romántico".

Intentando ampliar hasta el presente la panorámica que ofrece Gender und Media, se podría añadir que en el siglo XXI está ganando peso la teoría de la "sexualización" de la cultura. Las razones del éxito de la serie de ficción "Sexo en Nueva York" (Adriaens y Van Bauwel, 2011), el sexismo en la publicidad (Navarro y Martín, 2011), la reproducción de los estereotipos sexuales en la infancia o la cosificación de los cuerpos de las mujeres, que en la actualidad es claramente visible en los vídeos personales grabados por adolescentes en espacios privados y difundidos en la Red (Ringrose et al. 2013), son ejemplos del tipo de temas que se están abordando actualmente en el marco de la aproximación de género a la comunicación.

Sin negar que se han producido avances, un vistazo rápido a los contenidos mediáticos disponibles en la actualidad revela múltiples contradicciones, así como la no desaparición de los estereotipos ni de las estigmatizaciones construidas en torno al género. En referencia al primer punto, el de las contradicciones, es posible observar en una misma cadena diferentes grados de permisividad ante la opción sexual o encontrar mensajes homófobos junto a contenidos más abiertos hacia la diversidad sexual, por citar dos pruebas. Respecto al segundo punto citado, el de la persistencia de los estereotipos, también es frecuente encontrar ejemplos, como el caso de las "azafatas" en determinados concursos televisivos, cuya función es únicamente "decorativa", o la recurrente aparición de la homosexualidad bajo el código del género humor/comedia que, aunque ayuda a su visibilidad, no siempre se aleja de la estigmatización.

Finalmente, si seguimos estirando el hilo de la propuesta de Angerer y Dorer, es insoslayable referirse a la actual hibridación de los contenidos en las diferentes pantallas, resultado de la convergencia tecnológica. En este contexto, la Red, medio de comunicación con una expansión sin precedente en la historia de la comunicación, acoge en su seno los medios de comunicación tradicionales al mismo tiempo que potencia nuevas maneras de comunicar. Una de las consecuencias más innovadoras es 
la posibilidad que tienen ahora los públicos de participar en la realización de los contenidos. Nos referimos a la noción de "prosumer" o "audiencia creativa" (Martínez y De Salvador, 2014).

Teniendo en cuenta la posición central que ocupa hoy en día la Red en la vida cotidiana de la ciudadanía, su análisis desde la perspectiva de género se presenta como una cuestión urgente y esa es la razón por la que este artículo se enmarca en el estudio del entorno digital, atendiendo no solo al género sino también a la interculturalidad. Dado que las tecnologías de la comunicación se promulgan como nuevas vías de integración y participación social, es necesario comprobar hasta qué punto el acceso de las mujeres asegura realmente su empoderamiento (Castaño y Webster, 2014; Wajcman, 2006). Manuel Castells (2009) ha acuñado el término de "auto-comunicación de masas" y al hilo de su teoría la pregunta que nos hacemos aquí es: ¿̀hasta qué punto este empoderamiento incluye también al género marcado? O, en términos de Seyla Benhabib (2004; 2006), ¿̇se trata una vez más de una "universalidad sustitutoria"?

Para responder a estas cuestiones nos situaremos en un contexto de reflexión doblemente marcado: el de las mujeres migradas, aquellas que suman, a la discriminación de género, la de etnia $u$ origen cultural. Y lo haremos en un momento vital determinado: el de la adolescencia. Ełapa en la que se constituyen las identidades. Es decir, nos aproximaremos al estudio de un colectivo específico: la población adolescente migrante residente en España.

El desarrollo de la tecnología digital está enfatizando la necesidad no sólo de disponer de una identidad propia sino también de ser capaces de hacerla visible. Con el espacio digital surge un nuevo ámbito para la comunicación, caracterizado por la hibridación y reconfiguración de lo público y lo privado, que posicionan a éste como un escenario flexible en la construcción de las identidades.

En esta coyuntura, las perspectivas de la diversidad cultural y sexual se presentan fundamentales para poder desentrañar las particularidades de esta nueva plataforma mediática, utilizada por la ciudadanía para sus procesos de socialización tanto de carácter personal (por ejemplo, relaciones familiares) como colectivo (por ejemplo, participación política). Pero żhasta qué punto estas identidades digitales del colectivo migrante adolescente reproducen la identidad que los medios tradicionales han construido sobre ellos/as? Si tenemos en cuenta que generar nuevos discursos supone tener ideas alternativas y, al mismo tiempo, ser capaces de expresarlas con los códigos que nos impone el entorno digital, aparecen dudas sobre ese empoderamiento tecnológico. Sobre todo, si lo hacemos desde la perspectiva intercultural y de género.

Desde el año 2006, en el grupo de investigación Comunicación, Migración y Ciudadanía, ubicado en el Instituto de la Comunicación de la Universidad Autónoma de Barcelona (CMC InCom-UAB), venimos estudiando el consumo mediático-cultural de la población migrante interesados en conocer cómo se acaban combinando las culturas que la experiencia migratoria pone en contacto. En este texto, se presentan parte de los 
resultados del proyecto de investigación I+D+i que tenemos en marcha actualmente, "Las relaciones sociales de los jóvenes migrantes en Internet desde la perspectiva de la interculturalidad" (CSO2011-24376).

\section{Marco teórico}

\subsection{Brechas digitales}

Benítez (2011: 44) define la brecha digital como aquel fenómeno que "supone la consideración de una compleja serie de elementos simbólicos, relaciones de poder y normativas que posibilitan 0 excluyen a determinados grupos sociales de una participación plena en las redes de conectividad que dan forma a la sociedad Red" y Castaño (2009a), por su parte, distingue entre una primera versión, la de acceso, y una segunda, la de uso. Como indica Benítez, varios son los factores que inciden en esta exclusión, pero aquí incidiremos en dos aspectos. En primer lugar, la necesidad de enfatizar en el carácter transversal del género, ya que este es un factor que está íntimamente ligado con todas las variables que influyen en esta ecuación de exclusión (profesión, estudios, edad...). En segundo lugar, el modo en que la clase social condiciona tanto las posibilidades de acceso al entorno digital como la calidad del mismo lo que, en última instancia, repercute en los usos. Esto es, además de la oferta de servicios de conexión a Internet, en el mercado existe una amplia gama de equipos y precios con prestaciones diversas. Torres Albero y Robles Morales (2013), antes de que se advirtiera la envergadura de la actual crisis económica, ya pronosticaron que entre autóctonos y migrantes la brecha digital iría incrementándose con el paso del tiempo como consecuencia de la desigualdad económica.

Según registra la literatura científica (Aranda et al. 2010), la brecha digital del acceso en el conjunto del colectivo adolescente es prácticamente inexistente en cuanto a la variable de sexo. No obstante, en nuestros estudios sobre muestras poblacionales formadas por miembros de diversas raíces culturales, sí hemos registrado brecha de género de acceso muy marcada en un colectivo, el procedente del Magreb. Para empezar, en comparación con las migraciones originarias de Europa y Latinoamérica, este es el grupo con menor penetración de Internet. Según el Barómetro de la Comunicación y la Cultura (FUNDACC)' del año 2009, mientras que el $46 \%$ de los hogares extranjeros disponían de ordenador de sobremesa y el $45,4 \%$ tenían acceso a Internet; en el colectivo magrebí, la cifra se reducía hasta el $28,3 \%$ y $20,6 \%$ respectivamente. $Y$, en lo que al tema aquí tratado se refiere, aunque la juventud es en términos generales el principal usuario, la diferencia entre chicas y chicos aparece aquí muy pronunciada. Siguiendo la misma fuente estadística, se advierte que mientras que 6 de cada 10 adolescentes hombres magrebíes utilizaban Internet, en el caso de las mujeres adolescentes eran solo tres de cada diez (Huertas, Martínez y Moreras, 2012; Huertas y Martínez, 2013b). Nuestros estudios sobre este

1 FUNDACC, creada en 2005, es una fundación sin ánimo de lucro especializada en la investigación de consumos culturales en el mercado catalán. Su trabajo es pionero en España por la inclusión de población con nacionalidad no española en las muestras que emplea para sus sondeos. 
colectivo reflejan que la conexión a Internet se suele ubicar en el espacio de trabajo del padre/marido, evitándose su instalación en el hogar como "medida de protección" para los/as descendientes ante la difusión de valores y actitudes no aceptables para su cultura. Ahora bien, al mismo tiempo, cabe decir que eludir esta situación es más fácil para los adolescentes que para las chicas. Ellos tienen mayores posibilidades de recurrir a espacios públicos (locutorios, centros cívicos,...) que ellas, cuya vida está mucho más centrada en el ámbito doméstico, dada la fuerte incidencia de los estereotipos tradicionales que dividen el mundo en función del sexo de las personas y les asignan a estas las cualidades y roles correspondientes en la cultura de influencia de la religión musulmana, si bien es algo que se puede encontrar en todas las culturas en mayor o menor grado.

La segunda brecha, que remite a la desigualdad en los usos, se ve reflejada de forma generalizada en las mujeres migrantes en general, en todas las franjas de edad. De hecho, existen ya diversas teorías basadas en la definición de hábitos diferenciados en el comportamiento de hombres y mujeres en la Red. Desde el punto de vista cualitativo, se apunta a que mientras ellos dan a Internet un "uso tecnológico" (descargas de material audiovisual, de software...), ellas practican un "uso funcional/social" (educación, salud...) (Castaño, 2009b; Castaño, Martín y Vázquez, 2008). Desde el punto de vista cuantitativo, también aparecen divergencias (Aranda et al., 2010). Dos de ellas surgen de forma diáfana. En primer lugar, aunque la sociabilidad en el entorno digital está ampliamente extendida en el conjunto de la juventud, esta práctica tiene mucha más presencia entre ellas que entre ellos y, en segundo lugar, el uso de videojuegos on-line es una actividad apenas desarrollada por las mujeres. En este último caso, no podemos dejar de mencionar que el mercado, la oferta de videojuegos on-line disponible, ahonda en esa distinción (Arroyo, 2014).

Respecto al segundo punto, en nuestros análisis, hemos comprobado que dentro del colectivo migrante esta diferencia de usos entre hombres y mujeres tiende a darse de forma más acentuada que dentro del autóctono, muy especialmente en relación con la comunicación transnacional, una práctica inherente a la condición de migrante. La comunicación trasnacional, definida como el contacto con familiares y amistades que viven en otros países -ya sea en la zona geográfica de origen o en otras-, está mucho más presente entre las chicas que entre los chicos, en consonancia con las obligaciones establecidas por la cultura tradicional, que asignan a las mujeres el cuidado de la familia. Es decir, la variable de origen nacional o etnia se suma a la de género para dar como resultado un refuerzo del estereotipo tradicional que liga las mujeres a la esfera del cuidado y de los afectos (Huertas y Martínez, 2013a y 2013b; Martínez y Huertas, 2014).

\subsection{Visibilidad en las pantallas}

Una vez teorizado el contexto de las brechas digitales desde el género y la interculturalidad, nos disponemos a reflexionar acerca de la visibilidad de las minorías en la Red. Para los grupos discriminados, esta es una cuestión que se ve dificultada por la forma, es decir por el status. Son los sujetos quienes tienen la capacidad de nombrar el mundo, 
de ordenarlo, de contarlo... Son los sujetos a quienes se les brindan los altavoces del espacio público, de los medios de comunicación por tanto, para poder pronunciar sus discursos, en los que no solo se crean y recrean a sí mismos sino que también crean y recrean a los otros.

La dicotomía identidad-alteridad, yo y el otro, se presenta como la raíz del sistema dicotómico, característico del sistema de pensamiento racional que heredamos. En el fondo, la idea consiste en que existe algo que es considerado -el sujeto que nombra- y algo que queda fuera de toda consideración -el objeto nombrado: el otro-.

En la sociedad occidental, el polo de la identidad le está reservado al hombre blanco, burgués, protestante y heterosexual. Él es el sujeto que nombra, es el sujeto que tiene la palabra en exclusiva, el que habla en público, el que está presente en las redacciones mediáticas. Las mujeres, los migrantes, los negros, los indígenas, los pobres, quedan por exclusión situados en la alteridad, en el polo de ese otro que queda fuera -el objeto que es nombrado por otros y al que se le niegan los altavoces mediáticos- - .

En esta lógica dicotómica, las parejas de contrarios se multiplican (público/privado, modernidad/tradición, visible/invisible, sociedad/naturaleza, mente/cuerpo, hombre/mujer, autóctono/migrante), situándose la pareja positiva del binomio en el polo del sujeto que nombra, mientras que al otro se le asigna toda una serie de rasgos o características marcadas con la negatividad, empezando por la invisibilidad en la esfera pública, por el silencio en la tribuna mediática.

La lista de contrarios justifica "racionalmente" la división de espacios (público y privado) y la adjudicación de las tareas. Pertenecer al grupo de los otros comporta la exclusión del espacio público, aquel exclusivo de los sujetos, de los que nombran (Amorós, 2005). Los otros son invisibles, sin voz ni voto en la esfera mediática. El espacio privado se caracteriza por las emociones, la irracionalidad y la corporalidad. Cada individuo, en su posición de sujeto u objeto, incorpora los prejuicios, roles y estereotipos definidos por el propio espacio al que está asignado, ya que a cada esfera se le suponen una serie de actividades "naturales".

Los medios de comunicación tradicionales (la prensa, la radio, la televisión, el cine) producen y reproducen estereotipos y prejuicios de género y de etnia. Así, por ejemplo, las representaciones que hacen los medios tradicionales de los/las migrantes les niega la agencia y el reconocimiento de su subjetividad (Nash, 2005). Compartimos la visión de Mary Nash: "la invisibilidad y la falta de reconocimiento reproduce esquemas de subalternidad y la carencia del atributo de subjetividad a las personas inmigrantes genera visiones culturales estereotipadas de diversidad cultural en clave de otredad subalterna" (Nash, 2005: 25). Pero, como habíamos anunciado en el inicio del texto, la irrupción de Internet en el escenario mediático modifica la lógica dicotómica tradicional, al dislocar, al menos en potencia, el orden de varias parejas de contrarios. La Red supone (o permite suponer) el salto del objeto al sujeto, del nombrado al que nombra. El acceso a Internet les permite a los otrora objetos, a los antes nombrados por otros, a nombrarse a sí mismos, a 
hablar con sus propias voces, es decir, que les brinda un potencial espacio crítico-reflexivo desde el que llegar a ser sujetos.

Internet nos obliga, así, a repensar los viejos problemas y temas que giran en torno a la identidad de las minorías. En sintonía con lo expuesto hasta ahora, y en relación a la hibridación de los espacios público y privado en el entorno digital, destaca el juego temporal que hace Remedios Zafra (2010) con la reivindicación clásica del "cuarto propio" de Virginia Woolf2. Zafra habla del "cuarto propio conectado" como ese espacio donde "poder ser", aquel con "posibilidades de emancipación, concentración y producción (...) a través de las redes, como (por) las posibles formas de neutralización, aislamiento e invisibilización derivadas de la reconfiguración de estos espacios" (Zafra, 2010: 82). Como acabamos de anunciar, esta posibilidad dislocaría la pareja dicotómica público-privado y todo lo que ella comporta en cuanto a comportamientos y roles tradicionales aprehendidos. Pero żrealmente lo disloca? $\mathrm{Y}$, desde la perspectiva de nuestro análisis, ¿̇emplean las mujeres migrantes el entorno digital como tribuna mediática? Linda Leung (2007) ya describió la Internet de la década de los 90 del siglo XX como un espacio solo para la población blanca y masculina.

\section{Metodología: la muestra y el sistema de recogida de información}

En el proyecto de investigación I+D+i "Las relaciones sociales de los jóvenes migrantes en Internet desde la perspectiva de la interculturalidad" (CSO2011-24376), el trabajo empírico se desarrolló en las provincias de Barcelona, Vizcaya y Madrid entre enero y marzo de 2013. Se trabajó sobre una muestra de 72 personas (de 12 a 17 años), equilibrada en la variable de sexo (50\%). Según zona geográfica, el 30,5\% son de origen latinoamericano (la mayoría de Ecuador y Colombia), otro 30,5\% procede de África (fundamentalmente de Marruecos) y el resto (39\%), de Europa del Este (sobre todo, de Rumania). Aunque gran parte $(65,3 \%)$ vive con sus progenitores (con o sin hermanos/as), también es significativo el volumen de familias monoparentales, en concreto, jóvenes que viven solo con la madre (con o sin hermanos/as) (26,4\%). Por último, en relación al tiempo que llevan residiendo en España, más de la mitad de los miembros muestrales llegó antes de cumplir los 9 años $(59,7 \%)$ y el resto, o bien emigraron hacia España después de esa edad $(33,3 \%)$ o bien nacieron ya en este país (7\%).

Con la muestra se hicieron tres tipos de actividades. Se les convocó en grupos de 8 o 9 personas (todos formados por personas de la misma zona geográfica de origen y equilibrados por sexos), para la realización de focus groups (en total, se realizaron 9). Los encuentros tuvieron lugar en aulas de los centros escolares donde la muestra cursaba estudios en el momento del trabajo de campo. En total, se contactó con 13 institutos, repartidos por las tres provincias citadas. Antes de pasar a la dinámica habitual de este

2 En 1929, Virginia Woolf reivindica en su ensayo Una habitación propia, la necesidad para las mujeres de poseer un espacio propio y un sueldo de 500 libras para poder ser escritoras. 
tipo de técnica de recogida de información, se les aplicó un cuestionario semiestructurado individual y, a posteriori, se desarrolló un taller ad hoc.

El cuestionario, previo al diálogo, constaba de varios apartados, los cuales nos permitieron obtener datos cuantitativos. Los ejes temáticos tratados fueron: datos personales (edad, sexo, país de nacimiento propio/progenitores, años residiendo en España, información sobre las personas con las que se convive en el hogar), actividades preferidas en el tiempo libre, amistades (sexo, edad, país de nacimiento, lugar del primer encuentro, sociabilidad mediada, actividades de ocio compartidas), usos de Internet y de las Redes Sociales Digitales (RSD), comunicación transnacional, información audiovisual compartida en el entorno digital y percepción del riesgo en las Redes.

El debate propio del focus group sirvió para abordar, de una forma dialógica, los aspectos relacionados con las relaciones de amistad en los entornos online y offline. La moderadora adoptó aquí un papel semejante al de mediador intercultural y se preocupó por ahondar, sobre todo, en aquellas cuestiones difíciles de mesurar cuantitativamente: la actitud ante la posibilidad de conocer a personas de otro país/sexo, el grado de satisfacción de las amistades/actividades de ocio, la sensibilidad por proteger su privacidad y la vivencia de ataques racistas/xenófobos online. En trabajos de campo en contextos migratorios, es esencial que la persona que investiga adopte una actitud "provocadora", que no evite el conflicto intercultural y, además, que muestre valores éticos y predisposición moral en positivo, lo que no siempre resulta fácil.

El encuentro finalizaba con el desarrollo de talleres ad-hoc. Para ello, en cada focus group, se crearon dos subgrupos según el sexo y se abrió una discusión centrada, de forma específica, en la construcción de la identidad digital a partir de material visual (imágenes y fotografías) seleccionado por el equipo investigador. Estas imágenes fueron escogidas atendiendo a las siguientes nociones: (1) territorio-sentimiento de pertenencia (fotografías de paisajes, ciudades, banderas,... tanto del país de origen como del país de residencia); (2) cultura tradicional (cocina, trajes, artesanía...); (3) identidad religiosa (símbolos religiosos); (4) colectivos de pertenencia e interculturalidad (familia, relaciones de pareja, amistades); (5) identidad de género (diferentes roles profesionales, adscripción al espacio público/privado y sociabilidad-relaciones amistosas y familiares); (6) riesgo y seguridad en la Red, también planteado bajo una perspectiva de género (exhibición de cuerpo/sexualidad, espacio privado...). El objetivo de esta última actividad era identificar sus criterios a la hora de elegir imágenes auto-referenciales (identidad) destinadas al encuentro social digital (sociabilidad), "ver lo que ellos ven" (Banks, 2010: 22), centrándonos sobre todo en las dos variables que guían este estudio: género y origen cultural. 


\section{Resultados}

\subsection{Acceso y uso}

El 93\% por ciento de la muestra consultada tiene acceso a Internet y, en este sentido, no se encuentran diferencias según el sexo. En cambio, sí aparecen cuestiones que apuntan a la diferencia en los usos, aunque "estar con el ordenador" queda reflejada como una actividad habitual en el tiempo libre para el mismo porcentaje de hombres y mujeres $(33,3 \%)$. Por un lado, las actividades asociadas culturalmente al género masculino son marcadas mayoritariamente por los chicos (videojuegos online: $38,8 \%$ frente al $0 \%$ de las chicas o la búsqueda de información sobre viajes: $13,9 \%$ de los chicos frente al $2,7 \%$ de las chicas) y, por otro, aparecen comportamientos más extendidos entre las mujeres (búsqueda de información para actividades escolares: $86 \%$ de ellas frente al $61 \%$ de ellos; búsqueda de información sobre moda: $25 \%$ de ellas frente al 5,5\% de ellos), algunos, como el último caso de la moda, asociados tradicionalmente al estereotipo "femenino".

No obstante, también se evidencia equilibrio en la penetración de algunas tareas, con el mismo índice porcentual para ambos sexos: búsqueda de información sobre cine $(22,2 \%)$ y sobre música (16,6\%). E, incluso, encontramos datos que cuestionan estereotipos asignados culturalmente: el $62,7 \%$ de los internautas afirmaron cotillear en los perfiles abiertos por las amistades en las RSD, el 64,7\% de ellos y el 60,6\% de ellas. En el ranking de las actividades preferidas en Internet, el "cotilleo" se situó por detrás de chatear $(95,5 \%)$, comentar cosas (80,5\%), compartir fotografías $(71,7 \%)$ y utilizar el correo electrónico $(46,4 \%)$. Aunque en estas tareas registradas siempre es algo superior el índice de las chicas que el de los chicos, la mayor distancia según sexo se detecta en el uso del correo electrónico: $54,5 \%$ de ellas frente al $38,3 \%$ de ellos.

\subsection{Sociabilidad "on-line"}

Todos los componentes muestrales que utilizan Internet aseguran que emplean la Red para relacionarse con sus amistades (93\% de la muestra), pero las diferencias entre las mujeres y los hombres son notables:

- Entre ellas, son mayoría las que se relacionan con todas sus amistades (75\%), mientras que entre los hombres, aunque también el índice es elevado (61\%), es significativo el grupo que indica contactar con solo parte de sus amigos/as $(33,4 \%)$. 
Tabla 1. Relaciones amistosas en las Redes Sociales Digitales (RSD) de jóvenes migrantes en España

\begin{tabular}{|l|c|c|c|}
\hline & \multicolumn{3}{|c|}{$\begin{array}{c}\text { Dimensión de las relaciones amistosas } \\
\text { (\% sobre el total de la muestra) }\end{array}$} \\
\hline & $\begin{array}{c}\text { Con todas las } \\
\text { amistades }\end{array}$ & $\begin{array}{c}\text { Con parte de } \\
\text { las amistades }\end{array}$ & Con nadie \\
\hline General & 68 & 25 & 7 \\
\hline Hombres & 61 & 33,4 & 5,6 \\
\hline Mujeres & 75 & 16,7 & 8,3 \\
\hline
\end{tabular}

Fuente: Trabajo empírico desarrollado en las provincias de Vicaya, Madrid y Barcelona. 2013 (enero/marzo). Muestra: 72 personas de 12 a 17 años.

- Entre ellas, son mayoría las que tienen cuentas abiertas en tres RSD diferentes (49\% frente al $38 \%$ de ellos). O, dicho de otra manera, mientras que un $38 \%$ de los chicos tienen solo abierta una cuenta, este índice es del $21 \%$ entre las chicas. El tener cuentas en distintas redes aparece ligado a una especie de especialización. En estos casos, lo más común es destinar Facebook a las relaciones familiares; una segunda cuenta (Tuenti o bien Twitter), a las amistades y una tercera (normalmente gestionada desde los países de los que proceden), a contactos con personas con las que se comparten raíces culturales. En el colectivo procedente de Europa del Este se mencionó emplear las redes Vkontakte y NK; y en el de Latinoamericana, Hi5. De esta manera, la persona regula qué comunicar en los diferentes círculos amistosos y se acaba reproduciendo en el espacio digital la diversidad de relaciones/comportamientos que se tienen en el espacio físico.

\section{Tabla $n^{\circ} 2$. Presencia en las Redes Sociales Digitales (RSD) de jóvenes migrantes en España}

\begin{tabular}{|l|c|c|c|}
\hline & \multicolumn{3}{|c|}{ Número de perfiles abiertos en redes * } \\
& (\% sobre las personas que afirman tener presencia en las RSD) \\
\hline & 1 & 2 & 3 \\
\hline General & 29 & 27 & 44 \\
\hline Hombres & 38 & 24 & 38 \\
\hline Mujeres & 21 & 30 & 49 \\
\hline
\end{tabular}

Fuente: Trabajo empírico desarrollado en las provincias de Vizcaya, Madrid y Barcelona. 2013 (enero/marzo). Muestra: 72 personas (de 12 a 17 años)

- En la mayor parte de los perfiles se maneja un número de amistades de entre 61 y 500 (60\%), aunque este volumen es más frecuente entre las chicas (66,7\% de ellas) que entre los chicos (52,9\% de ellos). No obstante, cabe destacar que las redes digitales que superan las 500 amistades se corresponden mayoritariamente con perfiles de hombres, aunque el porcentaje solo sobrepasa en 5 puntos al de mujeres $(29,5 \%$ de ellos frente al $24,3 \%$ de ellas). 


\section{Tabla $\mathrm{n}^{\circ}$ 3. Volumen de amistades en las Redes Sociales Digitales (RSD) de jóvenes migrantes en España}

\begin{tabular}{|l|c|c|c|}
\hline & \multicolumn{3}{|c|}{$\begin{array}{c}\text { Número de amistades registradas en el perfil propio } \\
\text { (\% sobre las personas que afirman tener presencia en las RSD) }\end{array}$} \\
\hline $\begin{array}{c}\text { Nivel bajo } \\
\text { (entre 1 y 60) }\end{array}$ & $\begin{array}{c}\text { Nivel medio } \\
\text { (entre 61 y 500) }\end{array}$ & $\begin{array}{c}\text { Nivel alto } \\
\text { (entre 501 y 1.000) }\end{array}$ \\
\hline General & 13,5 & 60 & 26,5 \\
\hline Hombres & 17,6 & 52,9 & 29,5 \\
\hline Mujeres & 9 & 66,7 & 24,3 \\
\hline
\end{tabular}

Fuente: Trabajo empírico desarrollado en las provincias de Vizcaya, Madrid y Barcelona. 2013 (enero/marzo). Muestra: 72 personas (de 12 a 17 años)

\subsection{Visibilidad y autopercepción}

Siguiendo el discurso de Boyd (2008), a medida que se ha ido adquiriendo experiencia en el entorno digital se han ido estableciendo unos códigos de comunicación (por ejemplo, el uso de mayúsculas para expresar un grito o clicar sobre el icono "Me gusta" para dar a entender que se ha visto un contenido), de manera que ya es posible tipificar diversas categorías de usuarios según su comportamiento y actitud en la red. Para este trabajo, se definieron las siguientes categorías con las que los miembros de la muestra podían autoidentificarse: comentarista, líder, provocador, "troll" (internauta cuyo objetivo es molestar al resto, por ejemplo, desviando el tema de conversación planteado en un foro), creativo y curioso. Además, dimos la opción a que pudieran añadir otros adjetivos, si no se identificaban con ninguno de los propuestos, y, como consecuencia de ello, se decidió incorporar el término "normal" (dada su elevada presencia en las respuestas).

\section{Tabla n4. Autopercepción del comportamiento en las Redes Sociales Digitales (RSD) de jóvenes migrantes en España}

\begin{tabular}{|l|c|c|c|c|c|c|c|c|}
\hline & \multicolumn{7}{|c|}{ (\% sobre las personas que afirman tener presencia en las RSD)* } \\
\hline & Comentarista & Líder & Provocador/a & "Troll" & Creativo/a & Curioso/a & Normal & Otro** \\
\hline General & 58,4 & 21,5 & 12,3 & 9,2 & 44,6 & 6,1 & 15 & 9,2 \\
\hline Hombres & 51,5 & 15,1 & 15,1 & 15,1 & 33,3 & 6 & 13 & 12 \\
\hline Mujeres & 65,5 & 28,2 & 9,3 & 3,1 & 56,2 & 6,3 & 16 & 6,2 \\
\hline
\end{tabular}

Fuente: trabajo empírico desarrollado en las provincias de Vizcaya, Madrid y Barcelona. 2013 (enero/marzo). Muestra: 72 personas (de 12 a 17 años)

* Los porcentajes no suman $100 \%$ en horizontal, ya que podían escoger más de un calificativo.

** "Divertido/a", "detallista", "detective" (destacan cuantitativamente) 
En términos generales, son dos los adjetivos dominantes en este proceso de autodesignación: comentarista $(58,4 \%)$ y creativo/a $(44,6 \%)$. Y si se desglosan los datos en función del sexo se llega a la misma conclusión, aunque en ambos casos la conducta de ellas es la que ha influenciado más en esta tendencia. Pero, al mismo tiempo, se dan diferencias significativas porcentualmente. La proporción de "líderes" es superior entre ellas (28,2\% de ellas frente al $15,1 \%$ de ellos) y autodefinirse como troll es más común entre ellos (15,1\% frente a $3,1 \%)$. Ambas cuestiones no hacen otra cosa que marcar divergencias en cuanto al modo de ejercer la sociabilidad digital.

Por otro lado, las fotografías que emplean para identificar su perfil es un material de ineludible análisis para el tema que aquí nos ocupa y lo cierto es que se han obtenido conclusiones interesantes. El 33\% del conjunto de la muestra insistió en que siempre empleaba fotografías en las que aparecían contentos, conscientes de que esta imagen es esencial para construir un mensaje sobre sí mismos. Ahora bien, quedaron plasmadas diferencias según el sexo. Ellas indicaron que solían usar retratos donde aparecían con un rostro sonriente y ellos, fotografías rodeados de amigos (básicamente varones), lo que confirma las tendencias de reproducción de los estereotipos tradicionales de género. Ellas y la construcción sobre la belleza; ellos y la socialización en espacios públicos. Otros criterios que apuntaron tener en cuenta para la elección de la imagen del perfil, aunque en menor proporción, fueron: la estética de la fotografía (22\%) y salir favorecidos/guapos (16\%). De los/as 67 jóvenes con actividad en las RSD, solo una chica, de Marruecos, indicó preocuparse por indicar sus raíces culturales. En concreto, dijo utilizar una imagen de la bandera del Sahara.

\section{Conclusión final}

En primer lugar, observamos que Internet supone un espacio para la participación social, la sociabilidad y la autorreflexión accesible a aquellos individuos que los medios de comunicación tradicionales situaban en el par del binomio de la otredad, como es el caso del colectivo adolescente migrante $y$, muy especialmente, el caso de las mujeres. $Y$, aunque el comportamiento digital de este sujeto -con status recién estrenado- no muestra una autonomía trasgresora en la lógica dicotómica base de nuestro pensamiento racional, lo cual no dislocaría la pareja dicotómica de público/privado, sí se percibe, sin embargo, cierta vulneración de los estereotipos que hacen borrosas, pero sin llegar a desaparecer, las fronteras delimitadas por el género en los espacios tradicionales.

Más del $90 \%$ de la muestra consultada en este estudio tiene acceso a Internet, por lo tanto, la brecha digital de acceso según el sexo apenas es significativa. En cambio, no ocurre lo mismo con la brecha de los usos, donde sí aparecen divergencias. Ahora bien, el análisis de los usos desde la perspectiva de género muestra que cuando estos indican clara estereotipación de gustos e intereses según el sexo (por ejemplo, ellos: videojuegos y ellas: moda), los porcentajes de penetración no superan el 50\%. Y una interpretación similar se desprende de la sociabilidad digital. Si bien es cierto que esta se desarrolla en mayor grado entre las chicas, en consonancia con la cultura del cuidado y los afectos, la 
distancia entre los índices de las chicas y de los chicos no permite hablar de situaciones claramente opuestas.

Del conjunto de datos expuestos, el que más nos incita a la reflexión desde la perspectiva de género es el de la autopercepción de la conducta digital. Es aquí donde más distancias se hallan al comparar los índices. Al autodefinirse, la persona muestra aquello que considera que es (o pretende ser). De alguna manera, visibiliza aquel comportamiento que percibe como más adecuado. Y, aquí, los comportamientos más transgresores (provocador/a; troll) tienen más peso entre ellos que entre ellas, quienes parecen dar mayor cabida a expresarse abiertamente a través de comentarios textuales y actividades creativas (imágenes). Es una prueba de lo interiorizada y asumida que se tiene la heterodesignación, algo que se percibe como más palpable en la autopercepción que en el comportamiento.

Como conclusión general, se podría deducir de todo lo expuesto que las adolescentes migrantes consultadas están reproduciendo en un grado significativo los estereotipos tradicionales en esta fase del empoderamiento digital. Ahora bien, ello no compromete el devenir del futuro, ya que, como es sabido, los cambios sociales se producen de forma paulatina. 


\section{BIBLIOGRAFÍA}

ADRIANES, Fien; BAUWEL, Sofie van. "Remove from marked Records Sex and the City: a postfeminist point of view? Or how popular culture functions as a channel for feminist discourse. Journal of Popular Culture (Boston), Vol. 47, No. 1 (2011), pp. 174-195. DOl: $10.1111 / \mathrm{j} .1540-5931.2011 .00869 . x$

ANGERER, Marie-Luise; DORER, Johanna. Gender und Medien: theoretische Ansätze, empirische Befunde und Praxis der Massenkommunikation: ein Textbuch zur Einführung, Braumüller, Wien, 1994.

AMORÓs, Celia. La gran diferencia y las pequeñas consecuencias para las mujeres, Cátedra, Madrid, 2005.

ARANDA, Daniel; SÁNCHEZ NAVARRO, Jordi; TABERNERO, Carlos; TUBELLA, Imma. "Los jóvenes del siglo XXI: prácticas comunicativas y consumo cultural". Ponencia presentada en el II Congreso Internacional AE-IC (Málaga), 2010. Disponible en: [www.aeic2010malaga.org/upload/ok/204.pdf] Fecha de consulta: 1 de octubre de 2014.

ARROYO, Lidia. "La inclusión digital de las mujeres de clase trabajadora. Explorando caminos hacia una mayor igualdad". En CASTAÑO, Cecilia y WEBSTER, Juliet. Género, ciencia y tecnologías de la información. Editorial Aresta, Barcelona, 2014, pp. 115-140.

BANKS, Sarah. Ethical issues in youth work, Routledge, Londres, 2010.

BENHABIB, Sheyla. Las reivindicaciones de la cultura. Igualdad y diversidad en la era global, Katz, Buenos Aires, 2006.

BENHABIB, Sheyla. Los derechos de los otros. Extranjeros, residentes y ciudadanos, Gedisa, Barcelona, 2004.

BENÍTEZ, José Luis. Las comunicación transnacional de la e-familia migrantes. San Salvador, Programa de las Naciones Unidas para el Desarrollo (PNUD). Universidad Centroamericana "José Simeón Cañas" (UCA), San Salvador, 2011.

BOYD, Danah Michele. "Taken out of context: Teen Sociality in Networked Publics". PhD Thesis. Universidad de California, Berkeley, 2008.

CASTAÑO, Cecilia. "Los usos de Internet en las edades más jóvenes", CEE Participación Educativa, 11 (2009a), pp. 73-93.

CASTAÑO, Cecilia. "La segunda brecha digital y las mujeres jóvenes", Quaderns de la Mediterrània, 11 (2009b), pp. 218-224. 
CASTAÑO, Cecilia; MARTíN HERNÁNDEZ, Juan y VÁZQUEZ CUPEIRO, Susana. "La e-inclusión y el bienestar social. Una perspectiva de género. Economía industrial", Número 367 (Ejemplar dedicado a: Retos y oportunidades para el sistema productivo español) (2008), pp. 139-152.

CASTAÑO, Cecilia; WEBSTER, Juliet (Directoras). Género, ciencia y tecnologías de la información, Editorial Aresta, Barcelona, 2014.

CASTELLS, Manuel. Comunicación y Poder. Alianza, Madrid, 2009.

HUERTAS, Amparo; MARTíNEZ, Yolanda. "Población migrante y apropiación de las TIC desde una perspectiva feminista: reflexiones en torno a la comunicación transnacional en el colectivo adolescente", Telos, Cuadernos de Comunicación e Innovación, Número 96 (2013a), 37-46.

HUERTAS, Amparo; MARTÍNEZ, Yolanda. "Maghrebí Women in Spain: Roles in the Family and Media Consumption", Observatorio (OBS*) Journal, OberCom (Portugal). Special issue "Introducing Media, Technology and the Migrant Family: Media Uses, Appropriations and Articulations in a Culturally Diverse Europe" "Transforming Audiences, Transforming societies", $\quad 111-$ pp. $127 . \quad$ (2013b) Disponible en: [http://obs.obercom.pt/index.php/obs/article/viewFile/667/594] Fecha de consulta: 1 de octubre de 2014.

HUERTAS, Amparo; MARTíNEZ, Yolanda; MORERAS, Jordi. "Prácticas y consumos mediáticoculturales del colectivo marroquí en España (Documento de Trabajo)", Fundación Alternativas, Madrid, 2012.

LEUNG, Linda. Etnicidad virtual. Raza, resistencia y World Wide Web, Gedisa, Barcelona, 2007.

MARTíNEZ, Yolanda; HUERTAS, Amparo. "Las adolescentes migrantes ante las Tecnologías de la Información y la Comunicación (TICS): prácticas mediáticas y relaciones socioafectivas". En HUERTAS, Amparo y FIGUERAS, Mònica (Eds.). Audiencias juveniles y cultura digital, InCom-UAB, Barcelona, 2014. E-book disponible en: [http://issuu.com/incomuab/docs/ebook_incomuab_audienciajuvenilcult] Fecha de consulta: 2 de octubre de 2014.

MARTíNEZ SUÁREZ, Yolanda y DE SALVADOR AGRA, Saleta. "El produser como producción de usuarios: más allá de wreaders y de prosumers". Razón y Palabra, 86 (2014). Disponible en: [http://www.razonypalabra.org.mx/N/N86/V86/24_MartinezSalvador_V86.pdf] Fecha de consulta: 3 de octubre de 2014.

$\mathrm{NASH}$, Mary. Inmigrantes en nuestro espejo: inmigración y discurso periodístico en la prensa española, Icaria, Barcelona, 2005. 
NAVARRO BELTRÁ, Marian; MARTIN LLAGUNO, Marta. "El sexismo publicitario: delimitación de conceptos e indicadores de género. Estudio empírico de la producción científica", Pensar la publicidad, Vol 5, Número 1 (2011), pp. 51-73.

RINGROSE, Jessica; GILL, Rosalind, LIVINGSTONE, Sonia; HARVE, Laura. "Teen girls, sexual double standards and 'sexting': Gendered value in digital image exchange", Feminist Theory, Volumen 14, Número 3 (2013), pp. 305 - 323. DOI: 10.1177/1464700113499853

TORRES ALBERO, Cristóbal; ROBLES MORALES, José Manuel. "Internet y el proceso de inclusión vs. Exclusión digital de los inmigrantes en España", Revista Sistema, Volumen 229, Número 01 (2013), pp. 19-40.

WAJCMAN, Judy. El tecnofeminismo, Cátedra, Madrid, 2006.

ZAFRA, Remedios. Un cuarto propio conectado, Fórcola Ediciones, Madrid, 2010. 